\title{
Progressive Hemifacial Atrophy With Contralateral Uveitis: A Case Report
}

\author{
Onder Ayyildiz ${ }^{1, *}$; Simel Ayyildiz ${ }^{2}$; Ali Hakan Durukan ${ }^{1}$; Gungor Sobaci ${ }^{3}$ \\ ${ }_{1}^{1}$ Department of Ophthalmology, Gulhane Military Medical Academy, Ankara, Turkey \\ 2 2Department of Prosthodontics, Dental Health Sciences Center, Gulhane Military Medical Academy, Ankara, Turkey \\ ${ }^{3}$ Department of Prosthodontics, Dental Health Sciences Center, Gulhan \\ ${ }^{*}$ Corresponding Author: Onder Ayyildiz, Department of Ophthalmology, Gulhane Military Medical Academy, Ankara, Turkey. Tel:+90-5052538690, E-mail: dronderayyildiz@gmail.com
}

Received: July 3, 2014; Revised: September 9, 2014; Accepted: February 22, 2015

\begin{abstract}
Introduction: Progressive hemifacial atrophy, known as Parry-Romberg syndrome (PRS), was first described by Parry in 1825. There is a progressive atrophy of facial tissues including skin, bones and muscles. Ophthalmic disorders are common and include keratitis, uveitis, cataract, ipsilateral enophthalmos, optic neuritis, retinal vasculitis and scleral melting.

Case Presentation: We describe a patient with progressive hemifacial atrophy at right facial side who developed granulomatous uveitis and periferic retinal vasculitis in his left eye. We started topical and systemic steroid therapy. Uveitic reaction had regressed almost entirely after a 3-month steroid treatment.

Conclusions: The individuals should have multidisciplinary approach for the variety of disorders to maintain the appropriate treatment for a better appearance of the patients.
\end{abstract}

Keywords: Progressive Hemifacial Atrophy; Parry Romberg Syndrome; Uveitis

\section{Introduction}

Progressive hemifacial atrophy, known as Parry-Romberg Syndrome (PRS), was first described by Parry in 1825 (1). It was well-defined by Romberg in 1846 (2). It is a craniofacial disorder with onset in the first or second decade of life in individuals who are morphologically normal at birth (3). Hemifacial atrophy is a rare condition of unknown etiology, characterized by a slowly progressive atrophy of one side of the face, primarily involving the skin, subcutaneous fat, muscles and bones $(4,5)$. In addition to the progressive hemifacial atrophy, multiple accompanying disorders have been reported; ocular and neurologic changes and ipsilateral progressive body atrophy (4). Ocular involvement is commonly as fat loss around orbit leading to enophthalmos (6).

We describe a patient with progressive hemifacial atrophy who developed granulomatous uveitis at the opposite site. Also, there was posterior segment involvement in the form of periferic retinal vasculitis with optic neuritis.

\section{Case Presentation}

A 28-year-old male patient was referred to ophthalmology department of Gulhane Military Medical Academy in Ankara, Turkey, with blurred vision in his left eye in May 2010. His complaint developed 3 month ago. Visual acu- ity was 20/20 in both of his eyes. Biomicroscopy and fundoscopy findings were normal in the right eye. In his left eye, there was mutton-fat keratic precipitate, +2 anterior chamber cell and +2 vitreous cell in biomicroscopy and fundoscopy showed minimal optic disc hyperemia. Intraocular pressures, ocular motilities and pupil reactions of both eyes were normal (Table 1).

At the right side, there was madarosis of lateral part of upper and lower eyelid (Figure 1). There was an alopecia area at left eyebrow and a linear sclerotic lesion placed at his left forehead. Also, there was hemifacial asymmetry at his right part of face (Figure 2). Fundus fluorescein angiography (FFA) (HRA, Heidelberg Retinal Angiogram; Heidelberg Engineering GmBH, Dossenheim, Germany) revealed periferic retinal vasculitis and late phase optic disc hyperfluorescence in his left eye (Figure 3). Foveal thickness and retinal nerve fiber layer analysis in ocular coherence tomography (Stratus III OCT ${ }^{\mathrm{TM}}$; Carl Zeiss Meditec AG, Jena, Germany) was in normal ranges. Laboratory tests including blood count, erythrocyte sedimentation rate, routine chemistries, antinuclear antibody (ANA), antineutrophil cytoplasmic antibody (ANCA), anti-dsDNA, anticardiolipin and antiphospholipid antibody, fluorescent treponemal antibody absorption (FTA-ABS), anti-TORCH antibodies, C3, IgG and IgM, romatoid factor, C-reactive protein,

Copyright (C) 2015, Iranian Red Crescent Medical Journal. This is an open-access article distributed under the terms of the Creative Commons Attribution-NonCommercial 4.0 International License (http://creativecommons.org/licenses/by-nc/4.0/) which permits copy and redistribute the material just in noncommercial usages, provided the original work is properly cited. 
Ayyildiz $O$ et al.

serum angiotensin converting enzyme (ACE) levels, tuberculosis, Lyme and Brucella screening were normal. Dental consultation revealed no disorder in mouth, tongue and teeth. After physical examination and dental consultation, the patient was diagnosed as PRS with hemifacial atrophy at right facial side and after a detailed questionnaire the patient noted a subcutaneous fat injection under his right cheek. We diagnosed idiopathic granulomatous panuveitis in his left eye and started the topical and systemic steroid therapy. Uveitic reaction had regressed almost entirely after a 3-month steroid treatment.

Table 1. Patient Characteristics

\begin{tabular}{|c|c|}
\hline Variables & Characteristics \\
\hline Demographic data & A 28-year-old male patient \\
\hline Symptom & blurred vision in his left eye \\
\hline Duration of symptom & 3 months ago \\
\hline Visual acuity & $20 / 20$ in both of his eyes \\
\hline Biomicroscopy & $\begin{array}{l}\text { Right eye: normal, left eye: there was mutton-fat keratic precipitate, }+2 \text { anterior chamber } \\
\text { cell and }+2 \text { vitreous cell }\end{array}$ \\
\hline Fundoscopy & Right eye: normal, left eye: minimal optic disc hyperemia \\
\hline Intraocular pressure & Normal in both of his eyes \\
\hline $\begin{array}{l}\text { Ocular motilities and pupil } \\
\text { reactions }\end{array}$ & Normal in both of his eyes \\
\hline Periocular examination & $\begin{array}{l}\text { At the right side there was madarosis of lateral part of upper and lower eyelid. There was } \\
\text { an alopecia area at left eyebrow and a linear sclerotic lesion placed at his left forehead. Also, } \\
\text { there was hemifacial asymmetry at his right part of face. }\end{array}$ \\
\hline Fundus fluorescein angiography & Periferic retinal vasculitis and late phase optic disc hyperfluorescence in his left eye \\
\hline Ocular coherence tomography & Foveal thickness and retinal nerve fiber layer analysis was in normal ranges \\
\hline Dental consultation & Hemifacial atrophy of right facial side and no disorder in mouth, tongue and teeth \\
\hline Laboratory tests & Normal \\
\hline Previous treatment & Subcutaneous fat injection under his right cheek \\
\hline
\end{tabular}

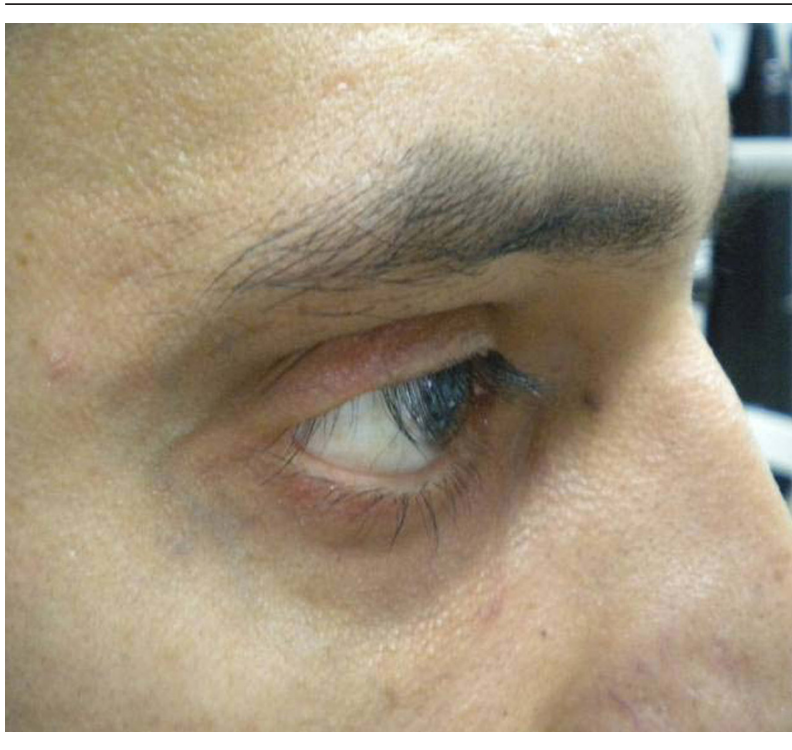

Figure 1. Madarosis of Upper and Lower Eyelid

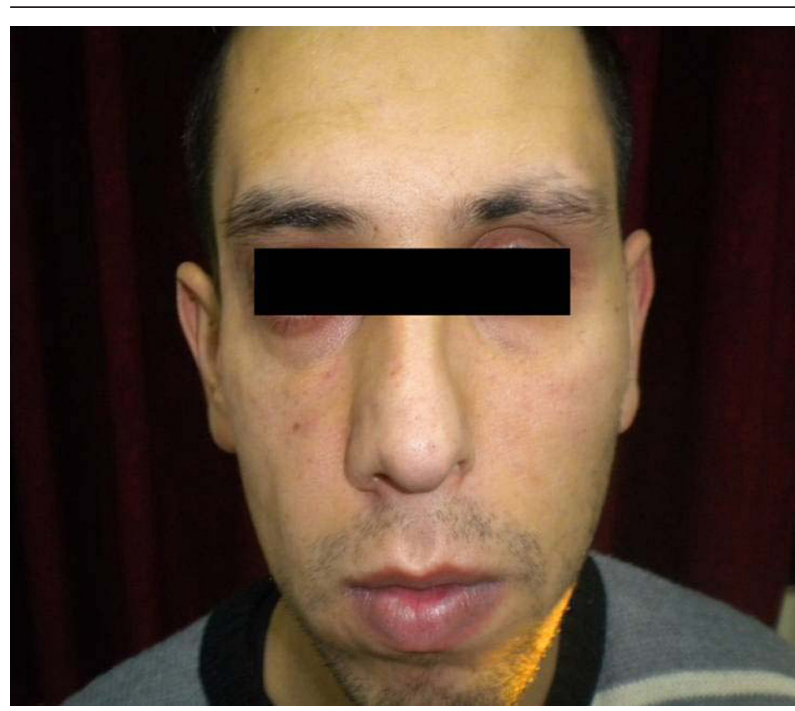

Figure 2. Hemifacial Asymmetry at Right Side of the Face and Alopecia at Left Eyebrow 


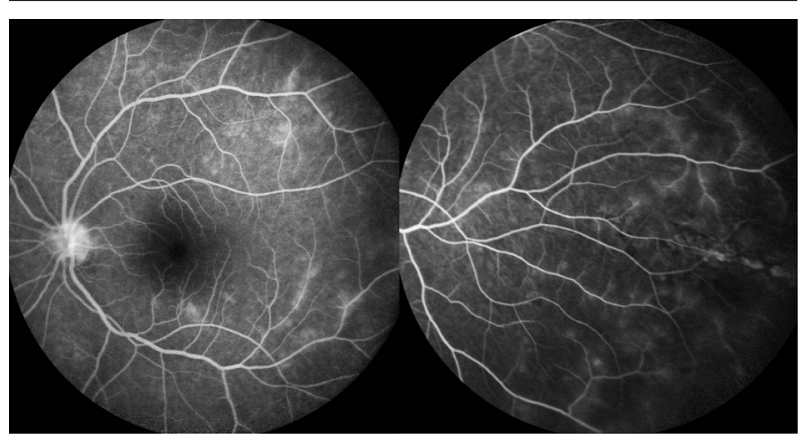

Figure 3. Periferic Retinal Vasculitis and Late Phase Optic Disc Hyperfluorescence

\section{Discussion}

The etiology of PRS is unknown and its pathology is rare. There are many hypotheses explaining the etiology; a relationship with either localized scleroderma, trauma, infection, an autoimmune disorder, a trigeminal neurovasculitis, heredodegenerative factors or a defect of the sympathetic nervous system have been suggested as possible causes $(4,5)$. There is a progressive atrophy of facial tissues including skin, bones and muscles $(4,7)$. The initial lesion in PRS is commonly a small area of abnormal pigmentation immediately superior to the eyebrow, then this lesion enlarges and becomes atrophic (8). There are patients presenting with a demarcation line between normal and abnormal skin, reminding a linear scar, known as 'coup de sabre', as we reported in this case (4, $9)$. Vitiligo, alopecia of the eyebrow and alopecic patches of the scalp were also reported (10). The most important features of this pathology are the enophthalmos, the deviation of mouth and nose to the affected side and unilateral exposition of teeth, among others $(4,9)$. Ophthalmic disorders are common and include keratitis, uveitis, cataract, ipsilateral enophthalmos, optic neuritis and atrophy, pupil anomalies ranging tonic to Horner pupil, heterochromia iridis, retinal pigmentary changes, progressive refractive changes, contralateral ocular muscle involvement, glaucoma, hypotony, retinal vasculitis, and scleral melting (3). Granulomatous uveitis with posterior segment involvement is a rare condition as we reported in our case. Also, we think it is an interesting condition that although hemifacial atrophy was at right side, the uveitis was in the left eye. Parry-Romberg syndrome is an auto-limitable condition and there is no certain cure (9). The presence of specific signs of PRS in this case and performing the appropriate examinations are the positive points of the present study. Our study limitation is the lack of previous history of the patient. The individuals should have multidisciplinary approach of physicians, dentists, phonoaudiologists and psychologists for the variety of disorders to maintain the appropriate treatment for a better appearance to the patients $(6,9)$.

\section{Authors' Contributions}

Study concept and design: Onder Ayyildiz, and Simel Ayyildiz. Drafting of the manuscript: Onder Ayyildiz. Critical revision of the manuscript for important intellectual content: Ali Hakan Durukan, and Gungor Sobaci.

\section{References}

1. Parry $\mathrm{CH}$. Collections from the unpublished medical writings of the late Caleb Hillier Parry.London: Underwoods; 1825.

2. Romberg HM. In klinische Ergebnisse.Berlin: Forstner; 1846.

3. Miller MT, Spencer MA. Progressive hemifacial atrophy. A natural history study. Trans Am Ophthalmol Soc. 1995;93:203-15.

4. Deshingkar SA, Barpande SR, Bhavthankar JD, Humbe JG. Progressive hemifacial atrophy (Parry-Romberg Syndrome). Contemp Clin Dent. 2012;3(Suppl 1):S78-81.

5. Chiu YE, Vora S, Kwon EK, Maheshwari M. A significant proportion of children with morphea en coup de sabre and Parry-Romberg syndrome have neuroimaging findings. Pediatr Dermatol. 2012;29(6):738-48.

6. Patel H, Thakkar C, Patel K. Parry-romberg syndrome: a rare entity. J Maxillofac Oral Surg. 2010;9(3):247-50.

7. Khan M, Khan M, Negi R, Gupta N. Parry Romberg syndrome with localized scleroderma: A case report. J Clin Exp Dent. 2014;6(3):e313-6.

8. Madasamy R, Jayanandan M, Adhavan UR, Gopalakrishnan S, Mahendra L. Parry Romberg syndrome: A case report and discussion. J Oral Maxillofac Pathol. 2012;16(3):406-10.

9. Pinheiro TP, Silva CC, Silveira CS, Botelho PC, Pinheiro M, Pinheiro Jde J. Progressive Hemifacial Atrophy--case report. Med Oral Patol Oral Cir Bucal. 2006;11(2):E112-4.

10. Janowska M, Podolec K, Lipko-Godlewska S, Wojas-Pelc A. Coexistence of Parry-Romberg syndrome with homolateral segmental vitiligo. Postepy Dermatol Alergol. 2013;30(6):409-11. 